\title{
De Consumidores a Coautores: Explorando o Design Participativo de Tecnologia Tangível em Contexto Educacional
}

\author{
Title: From Consumers to Co-authors: Exploring the Participatory Design of Tangible \\ Technology in an Educational Context
}

\author{
Bruna Zanetti Panaggio \\ Instituto de Computação, Universidade Estadual de \\ Campinas \\ brunazp@gmail.com
}

\author{
M. Cecília C. Baranauskas \\ Instituto de Computação, Universidade Estadual de \\ Campinas \\ cecilia@ic.unicamp.br
}

\begin{abstract}
Resumo
A tangibilidade dos sistemas computacionais está cada vez mais presente na vida cotidiana das pessoas, de forma que as crianças estão naturalmente imersas nesse mundo. Ao mesmo tempo em que a literatura acadêmica tem mostrado os benefícios das interfaces tangíveis em ambientes de aprendizado, ainda são raras as iniciativas que possibilitem aos educadores uma mudança de postura de consumidores a agentes ativos no design dessa tecnologia. Nesse contexto, este trabalho busca contribuir com o envolvimento de profissionais da Educação no design de sistemas móveis para o contexto educativo. O artigo explora técnicas do Design Participativo no design e desenvolvimento do Gira Letra, um aplicativo educacional voltado para o público infantil, que utiliza a bola robótica Sphero como uma interface tangível. O processo utilizado e resultados de três oficinas participativas que enfocaram a ideação e design do produto, bem como a avaliação de um protótipo criado para a plataforma Android são apresentados e discutidos. As oficinas foram realizadas em contexto escolar, em uma instituição que oferece educação suplementar, e contaram com a participação de crianças e professores. Os resultados sugerem a viabilidade do processo conduzido e apontam novos caminhos de investigação.
\end{abstract}

Palavras-Chave: Design Participativo; Interfaces Tangíveis; Sphero; Educação.

\begin{abstract}
The tangibility of computer systems is increasingly present in people's daily lives, so children are naturally immersed in this world. While the academic literature has shown the benefits of tangible interfaces in learning environments, initiatives that enable educators to shift consumers' positions to active agents in the design of this technology are still rare. In this context, this work seeks to contribute to the involvement of education professionals in the design of mobile systems for the educational context. The article explores Participatory Design techniques in the design and development of Gira Letra, an educational application aimed at children, which uses the Sphero robotic ball as a tangible interface. The process used and the results of three participatory workshops that focused on the product design and on the design and evaluation of a prototype created for the Android platform are presented and discussed. The workshops were carried out in a school context, in an institution that offers supplementary education, with the participation of children and teachers. The results suggest the viability of the process conducted and point out new avenues of investigation.
\end{abstract}

Keywords: Participatory Design; Tangible Interfaces; Sphero; Education.

Cite as: Panaggio, B. Z. \& Baranauskas, M. C. C. (2019). From Consumers to Co-authors: Exploring the Participatory Design of Tangible Technology in an Educational Context (De Consumidores a Coautores: Explorando o Design Participativo de Tecnologia Tangível em Contexto Educacional). Brazilian Journal of Computers in Education (Revista Brasileira de Informática na Educação - RBIE), 27(2), 91-111. DOI: 


\section{Introdução}

Os modos de interação com sistemas computacionais têm se transformado com base na evolução das tecnologias de acesso a esses sistemas. São chamadas 'interfaces tangíveis’ (TUIs - Tangible User Interfaces) aquelas que permitem que os usuários consigam interagir com informação digital por meio da manipulação de objetos físicos e do ambiente, em vez de utilizar periféricos tradicionais como mouse, teclado e monitor (Ishii e Ullmer, 1997). Em cenários de uso de tecnologias contemporâneas (ubíquas, pervasivas), as tecnologias de interfaces tangíveis dão forma física à informação digital ao empregarem artefatos físicos que servem como representações e controles para suas correspondentes digitais. As TUIs tornam a informação digital diretamente manipulável e perceptível por meio dos outros sentidos (Ishii, 2008).

O Sphero ${ }^{1}$, exibido na Figura 1, é um 'brinquedo inteligente', no formato de uma bola robótica que se conecta por Bluetooth a outros dispositivos compatíveis, como smartphones e tablets. Quando conectado, é possível controla-lo, alterando sua cor e fazendo o dispositivo se movimentar em várias direções e em diferentes velocidades. Além disso, o Sphero possui alguns sensores embutidos, como giroscópio e acelerômetro. Com as informações geradas por esses sensores, é possível utilizar outras funcionalidades, como a percepção da manipulação, detecção de colisão e queda, de modo que o objeto pode ser utilizado como um controle, monitorando os movimentos realizados com a mão. Por ser um objeto manipulável e controlável, o Sphero também pode ser considerado uma TUI.

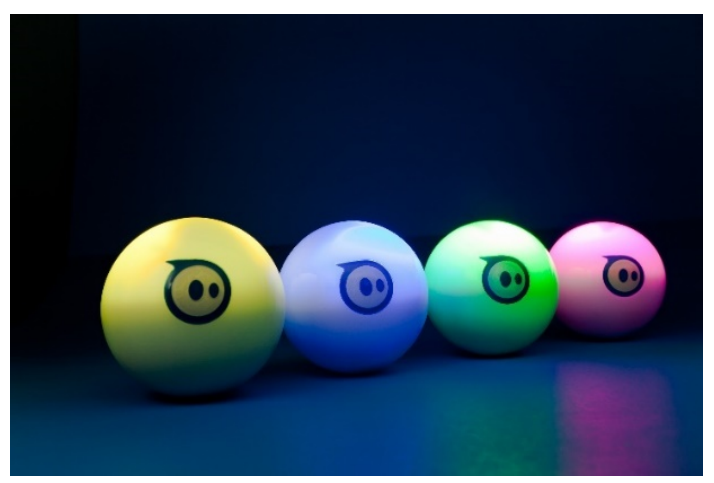

Figura 1: Spheros. Fonte: http://bit.ly/2JdVLQj. Acesso em maio de 2019.

Alguns aplicativos para smartphone que fazem uso do Sphero estão disponíveis no mercado. Por exemplo, o aplicativo Sphero Play ${ }^{2}$ fornece opções para o usuário controlar a bola robótica por meio do smartphone, alterando a direção e a velocidade do 'brinquedo inteligente', bem como alterando a sua iluminação. Nesse aplicativo também é possível utilizar o Sphero como um controle em alguns jogos, manipulando a bola com as mãos. Outro exemplo é o aplicativo Sphero Edu - Coding for Sphero Robots ${ }^{3}$, que permite a criação de programas com o uso de uma linguagem de programação baseada em blocos, para movimentar o Sphero, controlando a velocidade, o tempo e a direção dos movimentos.

Alguns benefícios são apontados quando se utiliza interfaces tangíveis na educação. As TUIs são capazes de promover um engajamento mais forte e de longa duração com um maior potencial para envolver as crianças durante atividades de aprendizado (Sylla et al., 2012), além de envolver todos os sentidos, apoiando o desenvolvimento geral da criança (Shaer e Hornecker, 2010) e evocar sentimentos de alegria e motivação (Posada et al., 2014). Além disso, as TUIs

\footnotetext{
${ }^{1}$ Sphero. https://www.sphero.com/sphero. Acesso em maio de 2019.

${ }^{2}$ Sphero Play. https://play.google.com/store/apps/details?id=com.sphero.spheromini. Acesso em maio de 2019.

${ }^{3}$ Sphero Edu. https://play.google.com/store/apps/details?id=com.sphero.sprk. Acesso em maio de 2019.
} 
promovem a acessibilidade, fornecendo mais opções a crianças com necessidades especiais e incentivam a aprendizagem em grupo; TUIs facilitam trabalho colaborativo e discussões (Zuckerman et al., 2005).

Diversos ambientes de aprendizagem baseados em TUIs se apresentam na literatura como o Touch\&Learn (Sánchez et al., 2011), que tem como objetivo aprimorar a experiência de crianças no aprendizado de idiomas mediante o uso de atividades que envolvem leitura e vocabulário e o CyberPLAYce (Soleimani et al., 2016) uma ferramenta de aprendizagem para crianças, tangível, interativa e cibernética, que apoia o pensamento computacional e o desenvolvimento de histórias de forma lúdica. Entretanto, pouco se tem encontrado sobre o processo de design de tais ambientes, como mostrado em Baranauskas e Carbajal (2017) que descrevem os processos de design utilizados para a construção do TaPrEC, um ambiente de programação tangível e de baixo custo proposto para trabalhar o pensamento algorítmico de forma lúdica com crianças. Neste trabalho argumentamos sobre a necessidade de envolver os educadores de forma direta no design de ambientes de aprendizagem baseados em TUI, e exploramos o assunto em um estudo de caso que utiliza o dispositivo Sphero no design participativo de um ambiente educacional.

A tangibilidade dos sistemas computacionais está cada vez mais presente na vida cotidiana das pessoas, de forma que as crianças estão naturalmente imersas nesse mundo. Ao mesmo tempo em que a literatura acadêmica tem mostrado os benefícios das interfaces tangíveis em ambientes de aprendizado, ainda são raras as iniciativas que possibilitem aos educadores uma mudança de postura de consumidores a agentes ativos no design dessa tecnologia. Nesse contexto, este trabalho busca contribuir com o envolvimento de profissionais da Educação no design de sistemas móveis para o contexto educativo, utilizando como abordagem metodológica o Design Participativo (DP).

No Design Participativo, os usuários são ativamente envolvidos em todo o ciclo de design e desenvolvimento do software. Muller et al. (1997) listam 61 práticas participativas para serem utilizadas em diversas fases do processo de design. Atividades participativas em grupo são conduzidas, em geral por especialistas em IHC (Interação Humano-Computador), e técnicas de DP são aplicadas nessas práticas.

Em parceria com professores de uma unidade de ensino, o PRODECAD ${ }^{4}$ (Programa de Desenvolvimento e Integração da Criança e do Adolescente), exploramos neste trabalho o uso de técnicas do Design Participativo em um processo focado em promover a participação ativa dos professores no ciclo de design e desenvolvimento de aplicativos voltados para o contexto educacional e para o público infantil, utilizando o Sphero como interface tangível. Objetivamos investigar e promover a participação de educadores como produtores de tecnologia, indo além do papel de consumidores.

O artigo está organizado da seguinte forma: a próxima seção contextualiza este trabalho; na sequência é apresentado o estudo de caso realizado, ilustrando todas as etapas do processo participativo: ideação, design, desenvolvimento e avaliação do sistema desenvolvido. Na seção seguinte, são apresentados e discutidos os resultados obtidos do estudo. Por fim, apresentamos as considerações finais do trabalho.

\footnotetext{
${ }^{4}$ PRODECAD. http://www.dgrh.unicamp.br/dedic/prodecad. Acesso em maio de 2019.
} 


\section{Contexto e Trabalhos Relacionados}

A presença da tecnologia computacional na vida cotidiana é um fato que não pode ser negado. E por ser necessária para atividades diárias básicas (Hourcade 2015), é praticamente impossível, e certamente indesejável, manter as crianças longe das tecnologias.

A Interação Criança-Computador refere-se a uma área de estudo que envolve o design, avaliação e implementação de sistemas computacionais interativos para crianças e os principais fenômenos que as cercam (Hourcade 2015). A área é importante pois os sistemas computacionais cada vez mais fazem parte da vida cotidiana, tanto de adultos como de crianças. À medida que as crianças crescem usando tais dispositivos mais frequentemente, a maneira como elas aprendem, jogam e interagem com os outros está mudando. As transformações, positivas ou não, dependem da forma como essas interações com os sistemas computacionais são projetadas e de como os dispositivos tecnológicos são usados; não há neutralidade na tecnologia. A Interação CriançaComputador é uma área que aborda como projetar tecnologia interativa para crianças e como as crianças podem tirar o máximo proveito dela para ter o impacto mais positivo em seu desenvolvimento. Read e Bekker (2011) fazem uma análise da área, investigando sobre o seu surgimento, e procurando entender as principais características e as principais diferenças em relação à área de Interação Humano-Computador (IHC). Os autores apontam que a Interação Criança-Computador estuda as atividades, comportamentos, preocupações e habilidades das crianças, estudando como elas interagem com tecnologias, sendo que muitas vezes o uso tem a intervenção de outros (principalmente adultos) em situações que eles parcialmente (mas geralmente não totalmente) controlam.

O envolvimento das crianças no processo de design de sistemas de tecnológicos pode ocorrer em diferentes níveis (Druin, 2002): como usuários, testadores, informantes e parceiros de design. Usuários e testadores são os menos envolvidos, já que eles utilizam tecnologia cujo design foi projetado por adultos (para crianças). Já informantes e parceiros de design trabalham junto com os adultos para criar o design da tecnologia, sendo que informantes são chamados para participar diversas vezes durante o processo de design nos momentos que suas informações são necessárias, enquanto que parceiros de design participam como uma parte interessada durante todo o processo.

Hourcade (2015) descreve atividades de design e avaliação baseadas nos papéis das crianças e um ciclo de vida típico de desenvolvimento de software, que inclui atividade de identificação de necessidades e estabelecimento de requisitos, o design da tecnologia, a implementação de versões da tecnologia e a avaliação (de requisitos, do design ou protótipos). Segundo Hourcade (2015), o levantamento de requisitos envolve o entendimento dos usuários e demais partes interessadas, e em quais contextos a tecnologia em desenvolvimento será utilizada. Para as tecnologias voltadas ao público infantil, requisitos de alto nível, como por exemplo, necessidades educacionais ou sociais das crianças, podem ser pesquisados. Em seguida, é necessário conduzir atividades para entender as crianças que irão utilizar a tecnologia no contexto definido. Nesse caso, partes interessadas chave, como professores e pais, podem prover informações antes de se trabalhar diretamente com as crianças. Por fim, atividades com crianças, como observações e entrevistas podem ajudar a alavancar os últimos requisitos.

Ainda de acordo com Hourcade (2015), para o desenvolvimento de ideias, algumas das atividades mais comuns são o brainstorm e o desenvolvimento de protótipos em diferentes níveis de fidelidade. No início do ciclo de vida, os protótipos tendem a ser de fidelidade menor com relação ao produto final, e utilizam materiais de artesanato. Como observa Hourcade, esses designs podem ser conduzidos com as crianças, já que esses materiais são de fácil acesso e manuseio; porém, argumentamos que, por outro lado, a baixa fidelidade exige da criança um nível 
maior de abstração, uma vez que tais protótipos se distanciam do produto final sendo criado, especialmente no que tange à sua funcionalidade. Mais para o fim do ciclo de vida, os protótipos podem ter maior fidelidade ao produto final e as características do público alvo, tipo de tecnologia e contexto de uso podem ajudar a definir cenários de design mais próximos do pretendido. Os métodos de avaliação podem ser também de vários níveis de formalidade: os mais informais, que envolvem feedback de crianças por meio de atividades que geralmente não exigem muito planejamento, ou por meio da observação direta, os mais formais, por exemplo a revisão por especialistas, que pode ser baseada em um conjunto de heurísticas que designers experientes utilizam para avaliar o protótipo sem o envolvimento de crianças, o teste de usabilidade, que consiste em um método formal para avaliar a tecnologia ou protótipo, entre outros.

Embora uma revisão sistemática da literatura esteja fora do escopo deste artigo, um estudo exploratório indicou que vários autores têm utilizado métodos e técnicas do Design Participativo para criar sistemas que atendam necessidades, interesses e expectativas das crianças no uso de tecnologia. Alguns trabalhos estão sumarizados na Tabela 1.

Pantoja et al. (2017) discutem em seu trabalho a abordagem utilizada e as sessões de design que serviram de base ao StoryCarnival, um aplicativo baseado na web voltado para crianças em idade pré-escolar, cujo objetivo é mediar brincadeiras de faz-de-conta que promovem a auto regulação. Nesse trabalho preliminar, os pesquisadores descrevem atividades realizadas com a colaboração de crianças, que atuaram como informantes no processo de design dessa tecnologia educativa. As crianças participaram de sessões de Imersão Tecnológica (Druin, 1999), nas quais houve a observação das crianças interagindo com aplicativos selecionados de diferentes modelos de dispositivos móveis; e sessões de Design da Experiência, cujo objetivo era apoiar o desenvolvimento de protótipos e a visão do produto. Apesar de professores terem acompanhado as atividades realizadas com as crianças, o trabalho não descreve as contribuições deles no processo de desenvolvimento do produto.

O Hemotion (Matsunaga et al., 2015) é um jogo educativo para crianças com hemofilia, que tem por objetivo informar, esclarecer e incentivar atitudes positivas das crianças em relação à doença com a qual elas terão que conviver. Desenvolvido em ambiente hospitalar, o protótipo apresentado utilizou algumas técnicas do Design Participativo e a participação de crianças com esse problema, além de contar com o apoio de médicos, fisioterapeutas, enfermeiros, pedagogos e psicólogos especializados na doença. As crianças atuaram como informantes, e participaram de sessões de prototipação interativa, e testaram protótipos funcionais desenvolvidos. O trabalho não informa as contribuições das demais partes interessadas no processo de design e desenvolvimento do jogo.

Já Arantes et al. (2012) apresentam uma abordagem metodológica semio-participativa, que tem base em conceitos e artefatos da Semiótica Organizacional, explorados de maneira participativa com as partes interessadas da escola (professores, gestores, alunos, pais, funcionários por ex. merendeira, bibliotecária, segurança, entre outros) em Projeto que visava a integração de laptops educacionais de baixo custo (laptop XO, um dispositivo durável, funcional, energeticamente eficiente, responsivo e divertido da $\mathrm{OLPC}^{5}$ ) no ambiente escolar. O trabalho descreve os resultados de algumas oficinas realizadas em contexto escolar com as partes interessadas mencionadas.

O CPES (Baranauskas e Posada, 2017) é um ambiente de narrativa tangível proposto para estruturar narrativas com o uso de elementos de interatividade, baseado nos conceitos de afetibilidade e nos princípios do Design Universal. O design do sistema foi um resultado de

\footnotetext{
${ }^{5}$ OLPC - One Laptop Per Child. http://one.laptop.org/. Acesso em julho de 2019.
} 
atividades semio-participativas, que contaram com a participação de diferentes partes interessadas, como pesquisadores, professores e estudantes, em oficinas conduzidas para discutir o design e o uso do sistema.

Braz et al. (2016) relatam as experiências das fases iniciais de um processo de design participativo de TUIs que pudessem ser utilizadas em contexto escolar para promover a educação inclusiva. Protótipos de baixa fidelidade desenvolvidos pelos autores foram utilizados em duas oficinas com a participação de professores, realizadas com a finalidade de entender se, e como, os professores se apropriariam da tecnologia proposta e se conseguiriam vislumbrar atividades que poderiam ser realizadas com os protótipos apresentados. Crianças não participaram das atividades.

Tabela 1:Sumário de trabalhos que utilizam técnicas do Design Participativo.

\begin{tabular}{|c|c|c|c|c|}
\hline Referência & $\begin{array}{l}\text { Sistema } \\
\text { tangível }\end{array}$ & $\begin{array}{c}\text { Envolvimento de } \\
\text { crianças }\end{array}$ & $\begin{array}{c}\begin{array}{c}\text { Envolvimento de } \\
\text { educadores }\end{array} \\
\end{array}$ & Limitações \\
\hline $\begin{array}{l}\text { Pantoja et al. } \\
\text { (2017) }\end{array}$ & & $\begin{array}{l}\text { Crianças participaram de } \\
\text { oficinas que informaram o } \\
\text { desenvolvimento de } \\
\text { protótipos e da visão do } \\
\text { produto } \\
\end{array}$ & - & $\begin{array}{c}\text { Não descreve o } \\
\text { envolvimento dos } \\
\text { professores na ideação do } \\
\text { sistema }\end{array}$ \\
\hline $\begin{array}{l}\text { Matsunaga et } \\
\text { al. (2015) }\end{array}$ & & $\begin{array}{l}\text { Crianças participaram de } \\
\text { oficinas que informaram o } \\
\text { design do protótipo e que } \\
\text { auxiliaram a avaliação do } \\
\text { mesmo }\end{array}$ & - & $\begin{array}{c}\text { Não descreve o } \\
\text { envolvimento dos } \\
\text { professores na ideação do } \\
\text { sistema; } \\
\text { Sistema educativo voltado } \\
\text { para a saúde } \\
\end{array}$ \\
\hline $\begin{array}{l}\text { Arantes et al. } \\
\text { (2012) }\end{array}$ & & $\begin{array}{l}\text { Crianças utilizaram o } \\
\text { dispositivo analisado }\end{array}$ & $\begin{array}{l}\text { Educadores participaram } \\
\text { de oficinas para analisar o } \\
\text { uso do laptop XO em } \\
\text { contexto escolar }\end{array}$ & $\begin{array}{c}\text { Não descreve o design de } \\
\text { um sistema; } \\
\text { Descreve o uso de um } \\
\text { dispositivo }\end{array}$ \\
\hline $\begin{array}{l}\text { Baranauskas e } \\
\text { Posada (2017) }\end{array}$ & $\checkmark$ & $\begin{array}{l}\text { Crianças participaram de } \\
\text { oficinas para discutir } \\
\text { design e uso do sistema }\end{array}$ & $\begin{array}{l}\text { Educadores participaram } \\
\text { de oficinas para discutir } \\
\text { design e uso do sistema }\end{array}$ & $\begin{array}{c}\text { Não descreve o } \\
\text { envolvimento dos } \\
\text { professores na ideação do } \\
\text { sistema }\end{array}$ \\
\hline $\begin{array}{l}\text { Braz et al. } \\
\quad(2016)\end{array}$ & $\checkmark$ & - & $\begin{array}{l}\text { Educadores participam de } \\
\text { oficinas para entender se } \\
\text { eles se apropriariam da } \\
\text { tecnologia proposta }\end{array}$ & $\begin{array}{c}\text { Não descreve o } \\
\text { envolvimento de crianças } \\
\text { na ideação do sistema }\end{array}$ \\
\hline
\end{tabular}

Apesar de a literatura apresentar diversos trabalhos com o uso de técnicas do design participativo para propor sistemas, tangíveis ou não, voltados para a educação das crianças, poucos focam nos educadores como produtores de tecnologia; isto é, em sua participação desde o processo de ideação, à criação e teste do produto, indo além de seu papel como consumidores de tecnologia para seu uso.

\section{Estudo de Caso}

As subseções a seguir descrevem o estudo de caso realizado para investigar o uso do design participativo no design de sistemas voltados para o contexto educacional e que utilizam o Sphero como parte de uma interface tangível.

\subsection{Sujeitos}

O estudo de caso foi conduzido no $1^{\circ}$ semestre de 2017, junto à Divisão de Educação Infantil e Complementar (DEdIC), mais especificamente na unidade do PRODECAD que fica localizada 
no campus da Universidade Estadual de Campinas (Unicamp), local onde esta pesquisa está sendo desenvolvida e os pais das crianças que frequentam a instituição trabalham. O PRODECAD viabiliza educação complementar em contraturno ao ensino regular, em espaço não formal, para crianças de 6 a 14 anos, matriculadas na Escola Estadual Sérgio Porto, localizada nas proximidades da universidade.

Participaram de diferentes etapas desse estudo de caso 19 pessoas do PRODECAD: 9 professoras, com idades entre 39 e 52 anos; e 10 alunos, com idades entre 8 e 10 anos, sendo 6 meninas e 4 meninos.

\subsection{Método}

Após a obtenção da aprovação da pesquisa pelo Comitê de Ética em Pesquisa da universidade, foi iniciado o estudo de caso que, no seu decorrer, contou com a realização de três Oficinas ${ }^{6}$ no espaço de 'ateliê' da instituição. A primeira etapa do estudo, a Oficina 1, realizada exclusivamente com professores, contou com atividades de design participativo para levantar ideias, requisitos e o design de aplicativos que utilizassem o Sphero em contexto educacional. Em seguida, foi realizada a codificação de uma das ideias levantadas, gerando um protótipo funcional de alta fidelidade. Depois da codificação, na fase seguinte, o sistema foi avaliado por professoras, na Oficina 2, e por crianças, na Oficina 3. Por fim, os resultados foram analisados pelos pesquisadores, gerando um ciclo de feedback que realimentou o design e desenvolvimento do sistema. A Figura 2 ilustra de forma resumida o processo metodológico utilizado neste estudo de caso. Este trabalho referese à primeira iteração desse processo, que pode ser repetido mais vezes para refinamento do produto.

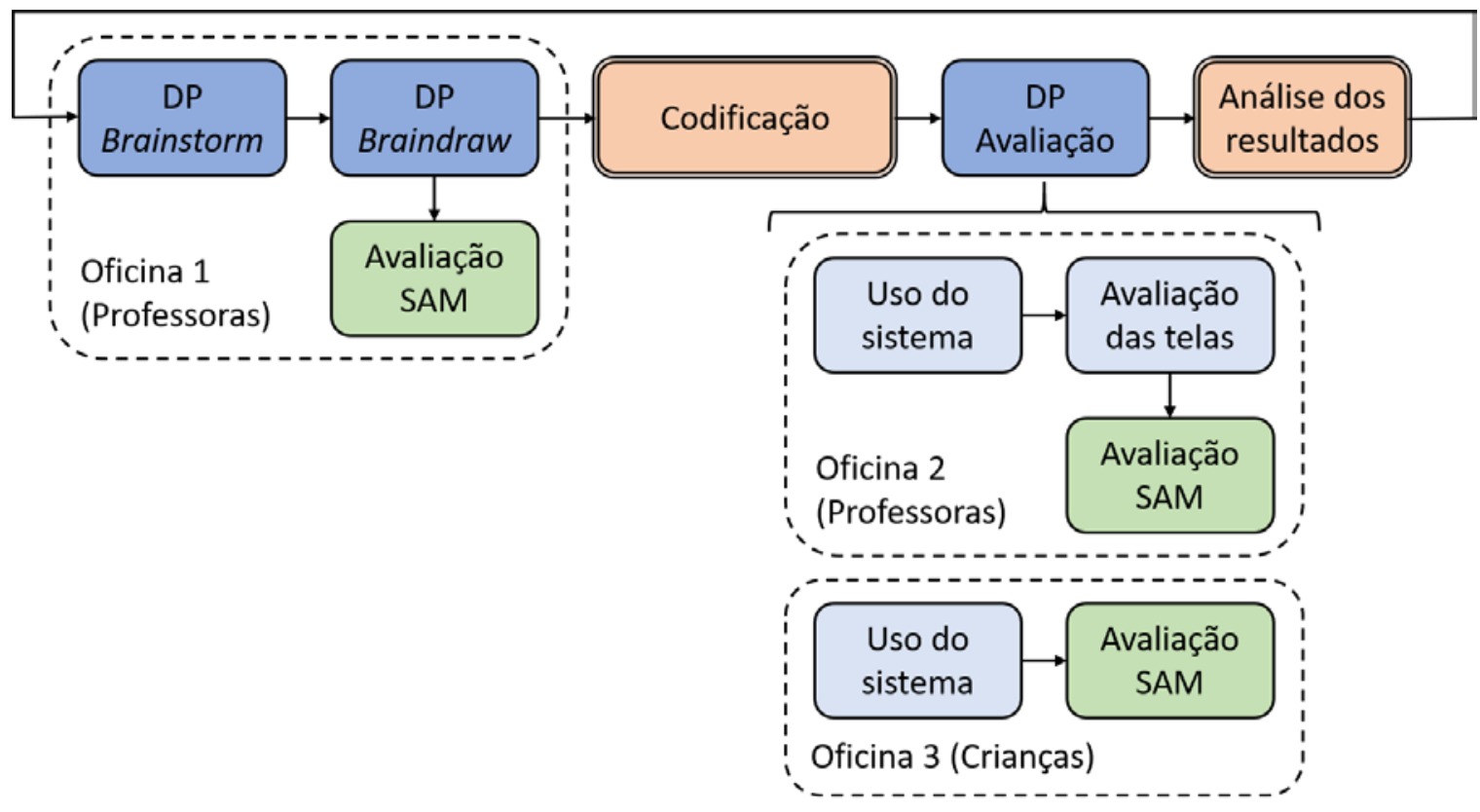

Figura 2: Processo utilizado neste estudo de caso. Fonte: dos autores.

A primeira fase do processo foi realizada em formato de Oficina com as professoras. As professoras foram distribuídas em dois grupos para executar as atividades, enquanto que os pesquisadores atuaram como observadores. Inicialmente, as professoras foram introduzidas ao brinquedo inteligente Sphero com uma breve apresentação. Nesse momento, elas também

\footnotetext{
${ }^{6}$ Projeto aprovado pelo Comitê de Ética em Pesquisa da Unicamp, sob número 32213314.8.0000.5404.
} 
puderam experimentar e conhecer a nova tecnologia, utilizando alguns dos aplicativos para smartphone disponíveis no mercado.

Em seguida foram aplicadas duas técnicas do Design Participativo: brainstorm e braindraw. Neste trabalho, a exemplo de Muller et al. (1997), brainstorm é entendido como a livre contribuição de ideias, sem medo de críticas ou avaliação, e com a suposição de que o grupo participante irá conduzir uma avaliação crítica dessas ideias com o grupo durante uma atividade subsequente. O braindraw (Muller et al., 1997) é um brainstorm "desenhado” no qual os participantes passam por folhas de papel preenchendo-as de forma incremental. Os participantes desenham as contribuições para um design gráfico inicial da interface de software por um tempo limitado, e depois passam a folha para o próximo participante, que complementa o desenho já iniciado. A mesma folha de papel é passada adiante, de forma que todos os participantes possam contribuir com todas as propostas dos demais participantes. Depois que todos os desenhos são finalizados, o grupo discute as ideias principais que emergiram nos desenhos e cria uma proposta final, com o consenso do grupo.

Com os resultados dessa primeira fase, iniciou-se a implementação do primeiro protótipo funcional de alta fidelidade, que foi desenvolvido para a plataforma Android.

Em seguida, já com o protótipo finalizado, foi iniciada a fase de Avaliação, que foi realizada em duas Oficinas, uma com o grupo de professoras e outra com o grupo de crianças. Professoras e crianças utilizaram o protótipo e responderam um breve questionário com sugestões de melhorias. As professoras, além dessas atividades, também avaliaram cada uma das telas disponíveis no protótipo.

Ao final das Oficinas, os participantes foram convidados a realizar uma autoavaliação de seu estado afetivo utilizando como instrumento o Self-Assessment Manikin (SAM) (Bradley e Lang, 1994). O SAM consiste de uma representação pictográfica na qual cada participante pode avaliar o sistema que está sendo utilizado em relação a três dimensões do aspecto afetivo: a Satisfação, a Motivação e o Controle. A Satisfação refere-se a quanto de alegria e contentamento o participante sentiu ao interagir com o sistema. Já o quesito Motivação reflete quanto o participante estava empolgado em utilizar o sistema. Por fim, o Controle refere-se ao domínio do participante em relação à utilização do sistema. Para cada uma dessas dimensões, a escala da resposta varia entre 1 e 9, na qual 1 representa o nível mais baixo e 9 o nível mais alto (de satisfação, motivação e controle). O SAM é uma ferramenta que possibilita avaliar a resposta afetiva tendo por base o modelo PAD (Pleasure, Arousal, Dominance), dimensões necessárias para uma descrição adequada da experiência emocional (Russell e Mehrabian, 1977).

\subsection{A Etapa de Brainstorm}

$\mathrm{Na}$ etapa de brainstorm, os dois grupos de participantes foram convidados a gerar ideias sob o tema: “Como a manipulação do Sphero pode ser utilizada no contexto educacional?”. Ao final dessa fase, foi solicitado que cada grupo realizasse um debate com as ideias propostas durante o brainstorm, e elegesse democraticamente a ideia mais interessante para a continuidade da Oficina.

Durante a primeira fase, que durou 15 minutos, as equipes geraram 4 ideias, todas voltadas para o contexto educacional. A Tabela 2 sintetiza as propostas.

Depois do debate entre os membros das equipes, o Grupo 1 optou pela ideia número 1, relacionada a dobraduras, enquanto que o Grupo 2 optou pela ideia 2, um jogo para adivinhar palavras. 
Tabela 2: Resumo das ideias geradas na fase de brainstorm.

\begin{tabular}{|c|c|c|}
\hline Número & Resumo & Uso do Sphero \\
\hline 1 & $\begin{array}{c}\text { Dobraduras: Um aplicativo para ajudar as crianças a fazer } \\
\text { dobraduras }\end{array}$ & $\begin{array}{c}\text { A manipulação do Sphero permitiria } \\
\text { uma visualização 3D do passo a passo } \\
\text { da dobradura }\end{array}$ \\
\hline 2 & $\begin{array}{c}\text { Gira Letra: Um jogo para adivinhar palavras, completando } \\
\text { letra por letra. Cada acerto está relacionado com uma } \\
\text { pontuação, que a criança deve calcular no final da rodada }\end{array}$ & $\begin{array}{c}\text { Ao girar o Sphero, seria possível } \\
\text { selecionar a pontuação de uma } \\
\text { determinada rodada }\end{array}$ \\
\hline 3 & $\begin{array}{c}\text { Labirinto: A criança deveria mover o Sphero com as mãos } \\
\text { para sair de um labirinto virtual }\end{array}$ & $\begin{array}{c}\text { A manipulação do Sphero permitiria } \\
\text { "caminhar” pela tela do smartphone }\end{array}$ \\
\hline 4 & $\begin{array}{c}\text { Ligar pontos: A criança deveria mover o Sphero com as } \\
\text { mãos para conectar dois pontos na tela do smartphone }\end{array}$ & $\begin{array}{c}\text { A manipulação do Sphero permitiria } \\
\text { "caminhar” pela tela do smartphone }\end{array}$ \\
\hline
\end{tabular}

\subsection{A Etapa de Braindraw}

$\mathrm{Na}$ etapa seguinte, foi utilizada a técnica de braindraw para que os participantes pudessem materializar no papel o design da ideia eleita para uma plataforma mobile. $\mathrm{O}$ foco foi o design da principal tela que faria uso do dispositivo Sphero e interação com a bola robótica e, para tal, foi fornecida uma folha de papel com a moldura de um smartphone e do Sphero. Foram realizadas duas iterações, sendo que cada iteração durou 4 minutos (1 minuto por participante). No final desta etapa, havia 4 propostas, e foi solicitado que cada grupo fizesse a consolidação das ideias geradas por todas as propostas em uma versão final.

A Figura 3 mostra os quatro designs propostos durante a fase de braindraw para o aplicativo de Dobradura e o aplicativo Gira Letra e o design consolidado proposto pelo Grupo 1 e 2 respectivamente.
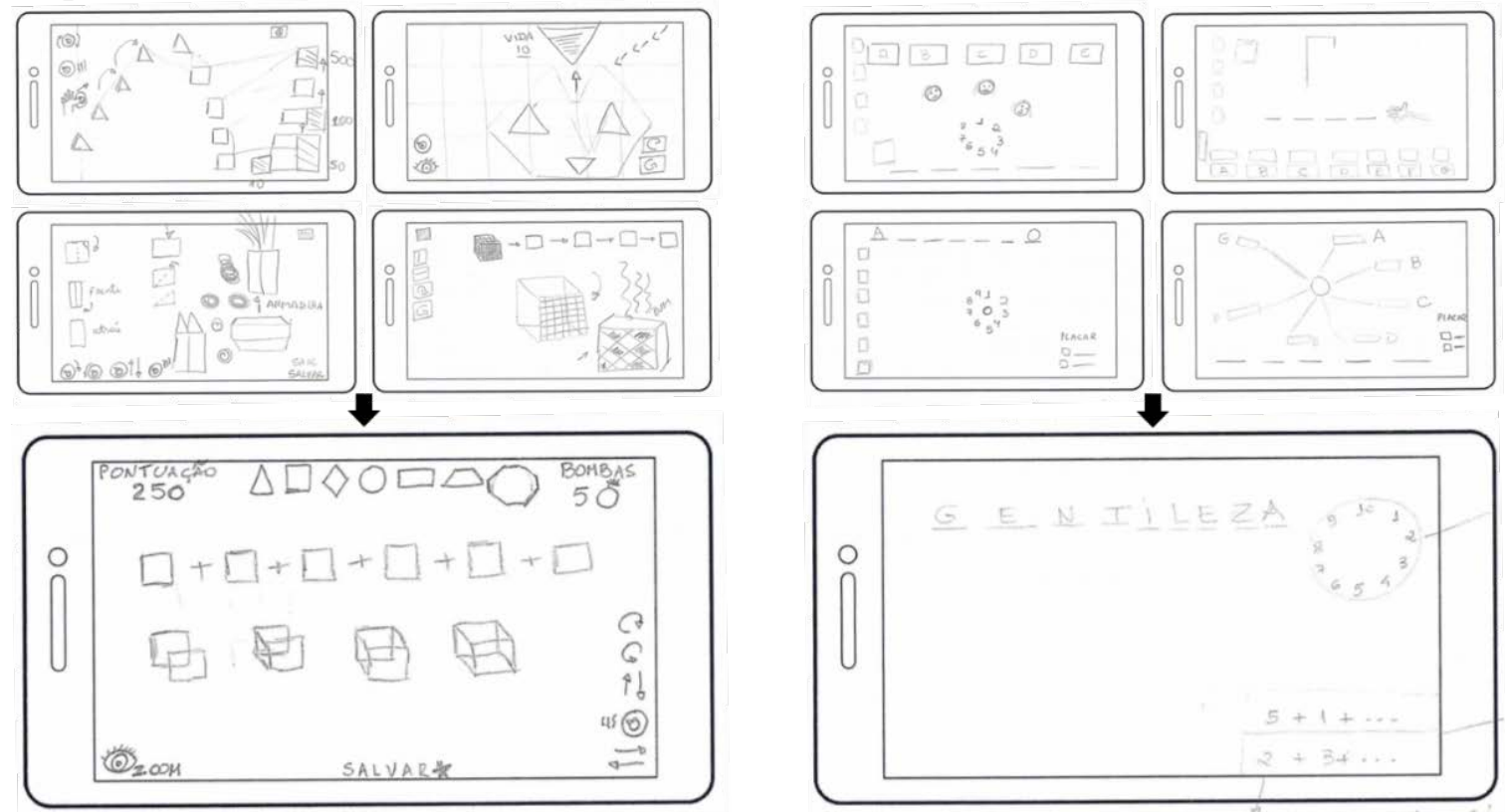

Figura 3: Os quatro designs propostos durante o braindraw e o design consolidado para o aplicativo. À esquerda, feito pelo Grupo 1, proposta para Dobradura. À direita, feito pelo Grupo 2, proposta para Gira Letra. Fonte: dos autores.

Por fim, os grupos apresentaram as ideias selecionadas e o design consolidado para os demais participantes da Oficina.

\subsection{A Etapa de Desenvolvimento}

Dentre as duas ideias propostas pelas professoras na fase de design participativo, os pesquisadores optaram por criar um protótipo para o sistema Gira Letra. Essa ideia foi escolhida por ser uma aplicação que, segundo as professoras, poderia trabalhar a parte de língua portuguesa, favorecendo 
o aumento de vocabulário das crianças e a parte da matemática, por exigir a solução de expressões matemáticas, em especial, contas de multiplicação. Além disso, as regras para o funcionamento do sistema foram bem detalhadas durante as fases de brainstorm e braindraw da Oficina.

Pensado para plataformas móveis, o Gira Letra foi proposto como um jogo para adivinhar palavras, completando-as letra por letra. Para tanto, quando uma jogada se inicia, uma palavra é sorteada, e para o usuário é apresentada a categoria a qual aquela palavra pertence, e lacunas que representam cada uma das letras da palavra. Antes de tentar adivinhar uma das letras que compõem a palavra, o jogador gira o Sphero em torno do seu próprio eixo vertical para sortear a pontuação da rodada, que pode variar entre 1 e 10 pontos: ao mesmo tempo que a bola robótica é girada no mundo físico, uma roleta virtual com as possíveis pontuações é apresentada para o jogador no smartphone. Com a pontuação sorteada, o usuário escolhe uma letra, e se ela estiver presente na palavra, as lacunas referentes são substituídas pela letra. O processo de sortear uma nova pontuação ao girar a roleta e testar uma letra é repetido até que todas as letras da palavra tenham sido reveladas e as lacunas preenchidas.

Em seguida, para continuar a sua jogada, o usuário deve calcular de forma correta a pontuação relacionada a cada letra, resolvendo contas de multiplicação: número de aparições da letra multiplicado pela pontuação sorteada na rodada em que a letra foi testada. Por fim, a pontuação final, que é calculada automaticamente pelo sistema e é resultante da soma de todas as multiplicações resolvidas na etapa anterior, é apresentada para o jogador.

Utilizando o design proposto para o Gira Letra, foi iniciado o desenvolvimento do sistema na plataforma Android. Para a conexão com o Sphero, foi utilizado o SDK Android para o Sphero ${ }^{7}$.

As principais funcionalidades descritas pelas professoras na primeira Oficina foram mapeadas para o aplicativo desenvolvido.

Como proposto pelas professoras durante as fases de brainstorm e braindraw, o Sphero faria o papel de 'roleta' para sortear a pontuação em uma determinada jogada. Para tal, o movimento do dispositivo em torno do seu eixo vertical foi monitorado para descobrir a rotação do dispositivo e assim mapear os valores relacionados da pontuação.

Por meio das APIs disponibilizadas pelo SDK para Android, é possível consultar os valores gerados pela Unidade de Medida Inercial (IMU - Inertial Measurement Unit), que contém acelerômetro e giroscópio. Para o Sphero, as informações sobre a rotação em torno do eixo vertical (Figura $4-$ yaw axis) variam entre $-180^{\circ}$ a $180^{\circ}$. Como a pontuação na roleta varia entre 1 e 10 pontos, cada $36^{\circ}$ da rotação do Sphero em torno do eixo vertical representa um ponto na roleta. $\mathrm{O}$ movimento em torno do eixo vertical foi mapeado em uma das telas do sistema, sendo que a representação digital gira ao mesmo tempo que o dispositivo físico está girando.

Em seguida foram criadas as demais telas do aplicativo (Figura 5). Para a tela que exibe as lacunas da palavra a ser descoberta, foram utilizados botões com todas as letras do alfabeto. Assim que uma letra é selecionada ela fica desabilitada para futuras seleções, e sua cor varia entre verde, para indicar que aquela letra está presente na palavra, ou vermelho, para indicar que não está. Para a tela de resolução de contas de multiplicação, uma lista apresenta cada uma das letras que compõem a palavra, e o usuário deve preencher com a resolução da expressão matemática (quantidade de aparições da letra multiplicado pela pontuação sorteada). Por fim, uma tela apresenta a pontuação final, e permite o início de uma nova rodada do jogo.

\footnotetext{
${ }^{7}$ Sdk Android para Sphero. https://github.com/orbotix/Sphero-Android-SDK. Acessado em junho de 2018.
} 


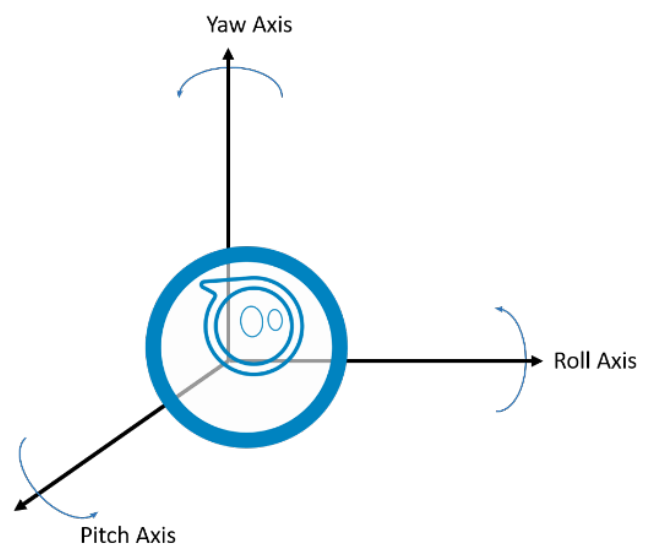

Figura 4: Rotação em torno do eixo vertical foi utilizada para a simulação de uma roleta de pontos. Fonte: dos autores.
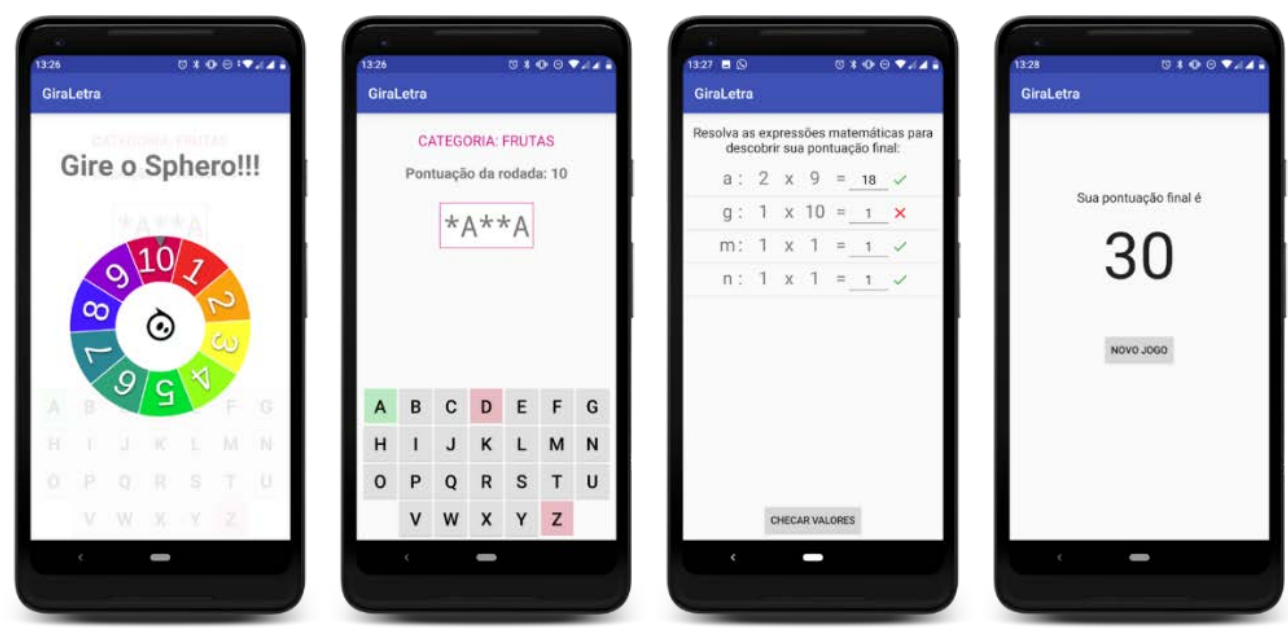

Figura 5: Da esquerda para a direita: a representação digital da roleta, controlada pelo Sphero; a tela de adivinhação de palavras; a tela para resolução das contas de multiplicação; tela com pontuação final. Fonte: dos autores.

\subsection{A Etapa de Avaliação}

A avaliação do sistema Gira Letra foi realizada em duas Oficinas, uma com a participação apenas de professoras e outra com a participação somente das crianças. As subseções a seguir descrevem os principais aspectos da avaliação do sistema Gira Letra.

\subsubsection{Objetivo}

O objetivo desta etapa era avaliar o aplicativo Gira Letra com potenciais usuários finais e entender se o design inicial foi efetivo e se ele produziu um resultado afetivo positivo nos jogadores, além de permitir entender as melhorias que poderiam ser realizadas em uma segunda versão do produto.

\subsubsection{Material e Dinâmica da Atividade}

Apesar de o sistema ter sido desenvolvido, inicialmente, para ser um jogo individual, durante as Oficinas de avaliação ele foi projetado em um monitor para que, enquanto um participante realizasse a sua jogada, os outros sujeitos pudessem observar (Figura 6). Para isso, um smartphone Android foi conectado a um computador utilizando um cabo USB.

Nas duas Oficinas realizadas, os participantes foram convidados a realizar uma jogada utilizando o sistema, ou seja, descobrir uma palavra associada a uma determinada categoria, resolver multiplicações e ver a pontuação calculada pelo sistema. 


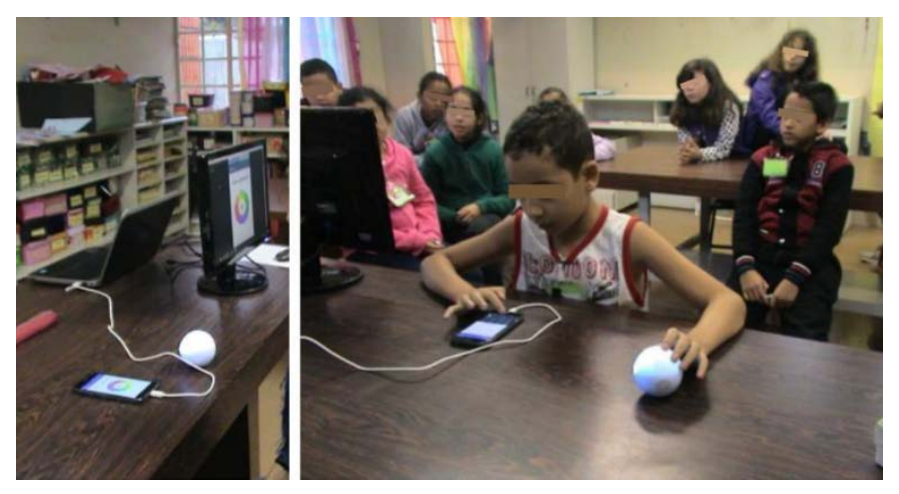

Figura 6: À esquerda, os equipamentos utilizados durante as Oficinas; à direita, uma criança realizando a atividade da Oficina, enquanto as demais observam pelo monitor. Fonte: dos autores.

Na Oficina realizada com as professoras, 5 sujeitos jogaram com a categoria "Emoções”, enquanto os demais observaram. Depois de realizar essa atividade, todos os participantes responderam um questionário com questões abertas e também realizaram a autoavaliação de estado afetivo utilizando o SAM. Além disso, os participantes fizeram uma avaliação de cada uma das telas do sistema (Figura 7), expressando a sua satisfação com aquela tela e propondo sugestões. Para essa avaliação, extraímos a representação pictográfica relacionada a "Satisfação" do SAM, e utilizamos a mesma escala: 1 para quando o avaliador estivesse pouco satisfeito com a tela avaliada e 9 para quando estivesse muito satisfeito.
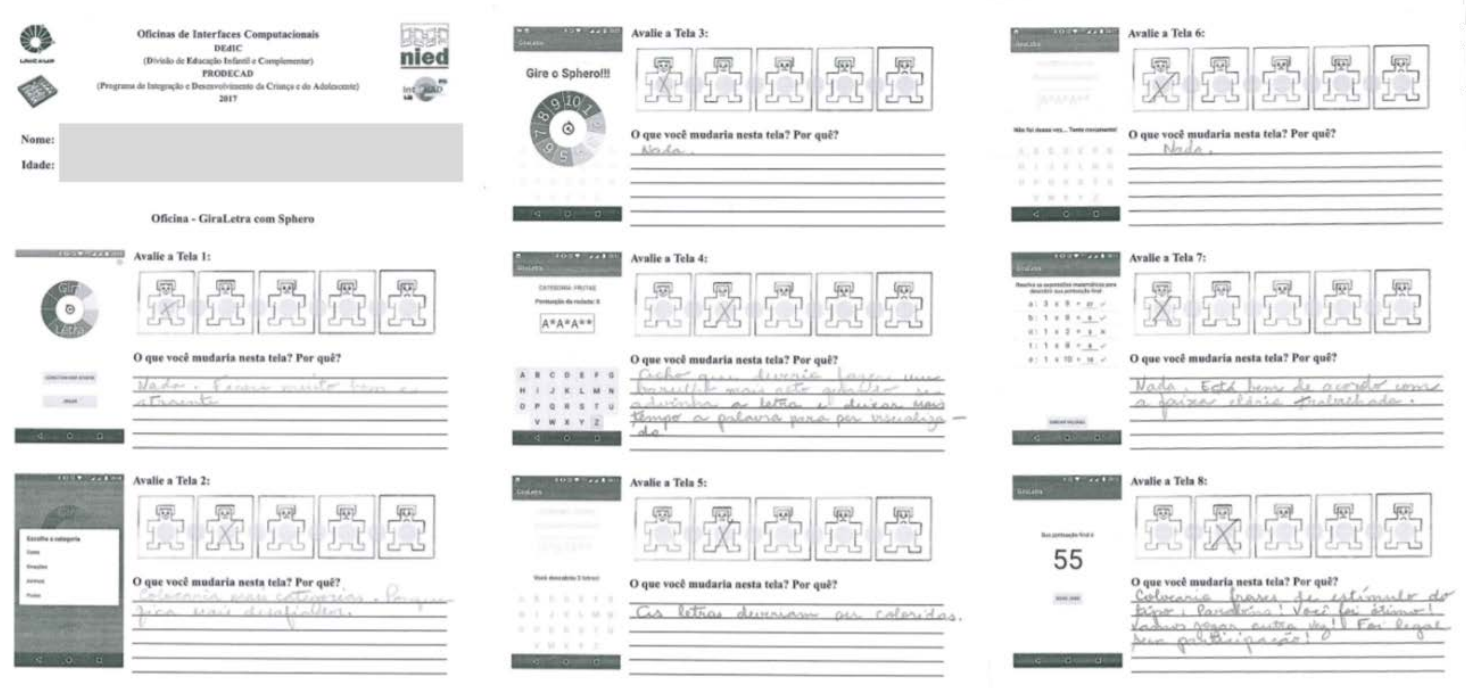

Figura 7: Formulário de avaliação das telas do sistema. Para cada tela, o participante deveria informar a sua satisfação com a tela e sugerir melhorias. Fonte: dos autores.

Na Oficina realizada com as crianças, elas foram distribuídas em duas equipes, e todas jogaram sob a categoria “Animais”. Cada equipe teve um responsável por anotar na lousa a quantidade de pontos somados por um jogador ao final de uma rodada, quando o jogador descobria a palavra por inteiro. Assim que cada participante da Oficina jogou uma vez, foi realizada a soma das pontuações anotadas na lousa, para definir a equipe que fez mais pontos. Por fim, os participantes responderam um questionário com questões abertas e realizaram a autoavaliação de estados afetivos utilizando o SAM (Figura 8). 

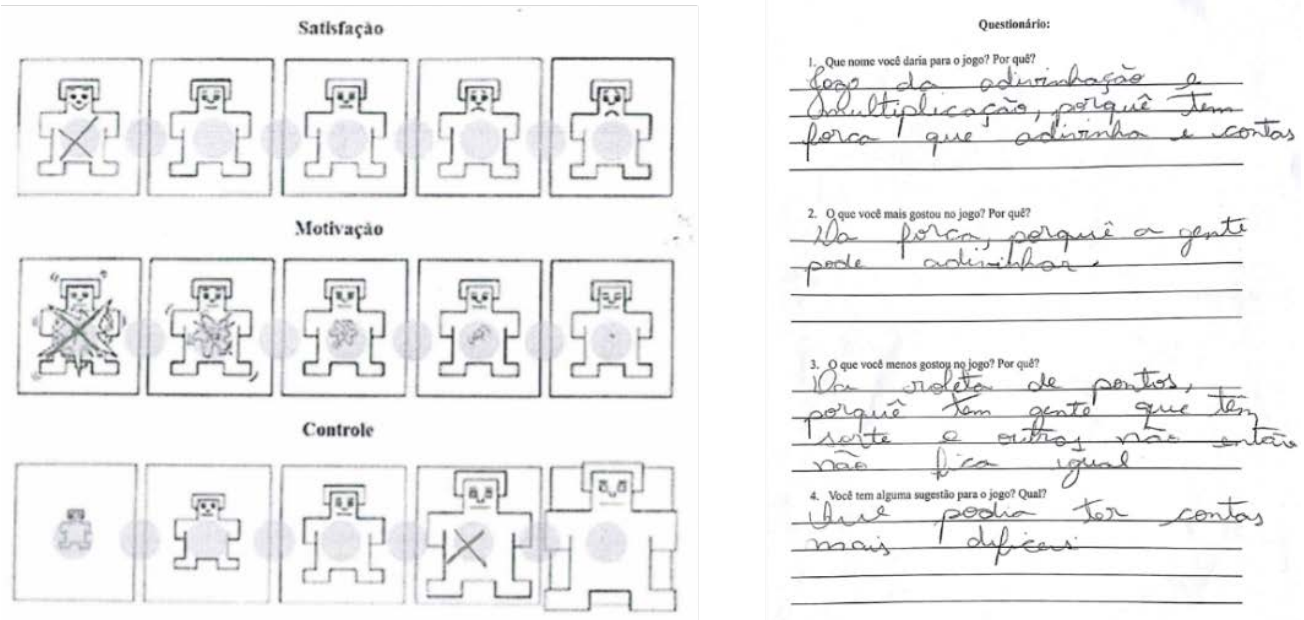

Figura 8: À esquerda, o formulário utilizado para a autoavaliação de emoções preenchido por um dos participantes; à direita o questionário aberto com perguntas sobre o aplicativo. Fonte: dos autores.

Além disso, as Oficinas foram gravadas em vídeo para uma análise posterior. Portanto, a análise desse estudo contou com as respostas para os questionários abertos, o SAM e a análise dos vídeos.

\section{Resultados}

As subseções a seguir descrevem os principais resultados obtidos pela avaliação de telas do sistema realizada pelas professoras, da autoavaliação de estados afetivos preenchido por professoras e alunos durante as Oficinas, e das observações dos pesquisadores feitas durante o uso do sistema. Por fim, apresentamos uma discussão dos resultados obtidos.

\subsection{Da Oficina de Design Participativo}

Na Oficina 1, depois de conhecer o Sphero e de concluir a primeira etapa do design participativo, com as atividades de brainstorm e braindraw, cada professora realizou a autoavaliação de estados afetivos.

A Tabela 3 sintetiza a moda dos valores respondidos pelas professoras para cada uma das três dimensões do aspecto afetivo. Os resultados são exibidos para o Grupo 1, que trabalhou com a ideia de Dobraduras, para o Grupo 2, que trabalhou com a ideia do Gira Letra, e para todos os participantes de maneira geral, sem considerar a divisão dos grupos. Como é possível observar, se considerarmos os participantes como um todo, sem a divisão de grupos, a avaliação para cada uma das três dimensões do aspecto afetivo foi neutra (moda 5). No Grupo 1, a avaliação do aspecto Satisfação foi positiva (moda 9), enquanto que para o aspecto Motivação a avaliação ficou neutra (moda 5) e para o aspecto Controle, houve divisão de opiniões (moda 3 e moda 7). No Grupo 2 a avaliação foi mais uniforme: para os três aspectos a avaliação foi neutra (moda 5). No Grupo 2 não houve nota positiva para as dimensões do SAM.

Tabela 3: Moda dos valores respondidos pelas professoras para cada uma das três dimensões do aspecto afetivo.

\begin{tabular}{|c|c|c|c|}
\hline Aspecto Afetivo & Grupo 1 & Grupo 2 & $\begin{array}{c}\text { Todos os } \\
\text { participantes }\end{array}$ \\
\hline Satisfação & 9 & 5 & 5 \\
\hline Motivação & 5 & 5 & 5 \\
\hline Controle & 3 e 7 & 5 & 3 e 5 \\
\hline
\end{tabular}


Na apresentação de introdução ao Sphero as professoras estavam curiosas e tiraram muitas dúvidas sobre o novo dispositivo. Na atividade de brainstorm, elas foram bem participativas, e sugeriram ideias sobre o uso do Sphero no contexto de suas atividades educacionais, expressando algumas vezes alguns questionamentos sobre a possibilidade da implementação das ideias. Já durante a atividade de braindraw, as professoras utilizaram frases como "Eu não sou capaz", "Isso é muito difícil" e "Desenhar não é minha área” para expressar o seu desconforto com a atividade proposta. Esse comportamento foi refletido no SAM. Entretanto, os dois grupos foram capazes de concluir as atividades propostas na Oficina 1 (os resultados já foram destacados na Tabela 2 e Figura 3), e os membros de cada grupo fizeram uma breve apresentação de sua ideia selecionada e do design consolidado para os demais presentes na Oficina.

\subsection{Da Avaliação das Telas do Sistema}

Cada professora preencheu um formulário para avaliar as telas do aplicativo. Para cada tela, foi solicitado que elas preenchessem a satisfação com a tela e escrevessem sugestões de melhorias. Classificamos as sugestões dadas pelas professoras em duas categorias: "Nova funcionalidade" refere-se às sugestões dadas pelas professoras de novas funções para o sistema que não haviam sido propostas na Oficina 1; já “Aprimoramento” refere-se às sugestões que geram uma melhoria em funcionalidades propostas anteriormente.

A Figura 9 apresenta a satisfação das professoras com cada uma das telas e a Tabela 4 sumariza as sugestões feitas pelas professoras. A Tela 1, a primeira com a qual um usuário entra em contato com o sistema, foi a mais bem avaliada pelos participantes, e inclusive gerou um elogio: “Ficou muito bom e atraente.”. É possível notar que não houve sugestões para melhorar a representação virtual da roleta (Tela 3), e também não foi mencionada a interação entre Sphero e essa representação virtual em nenhum dos comentários.

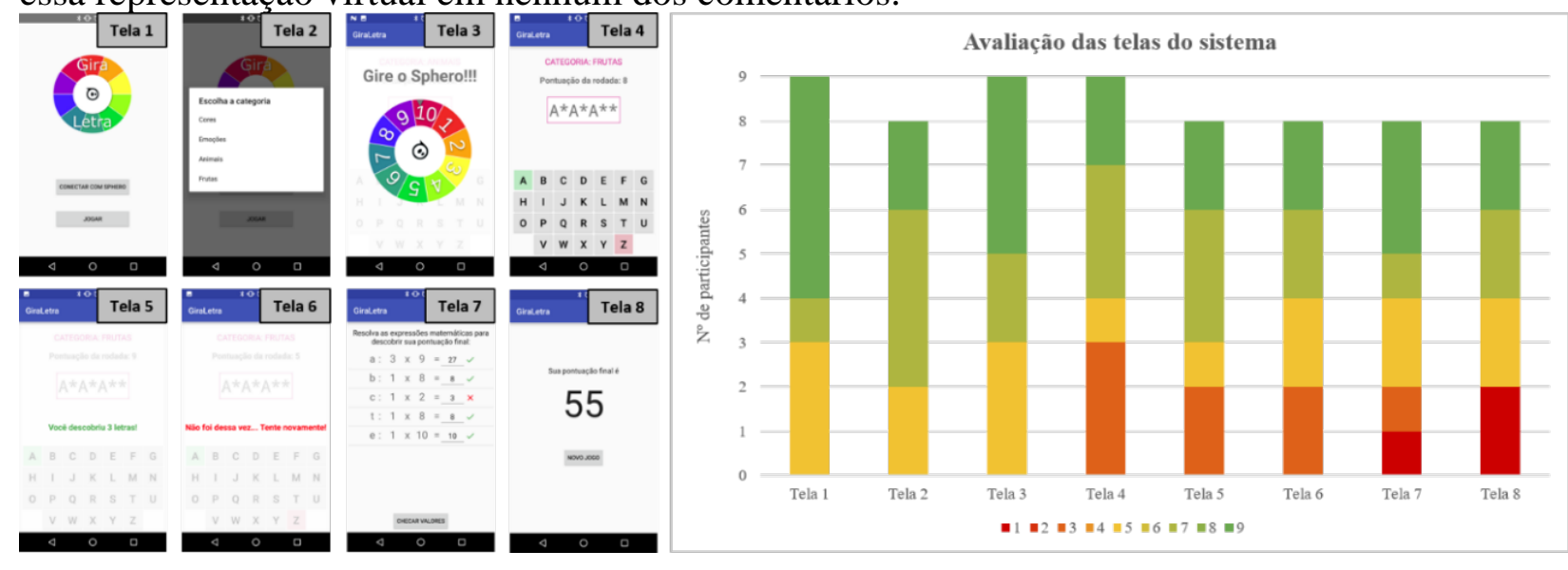

Figura 9: À esquerda, as telas usadas na avaliação; à direita, a satisfação com cada uma dessas telas. Fonte: dos autores.

A Tela 8, que apresenta a pontuação final da rodada foi a pior avaliada pelos participantes. Os participantes expressaram a necessidade de mostrar que a pontuação está associada com as contas de multiplicação realizadas na tela anterior, já que crianças podem sentir que estão sendo avaliadas, e se sentir pressionadas. As professoras também sugeriram que as pontuações sejam convertidas em outros itens, como estrelas e corações, para que seja retirado o estigma de uma prova ou avaliação. Esses itens poderiam ser utilizados em outras telas do jogo, para desenvolver novas funcionalidades sugeridas, como dicas para descobrir uma nova palavra. 
Tabela 4: Sugestões de melhorias e novas funcionalidades propostas pelas professoras.

\begin{tabular}{|c|c|c|}
\hline Tela & Sugestão & Categoria \\
\hline 1 & - & - \\
\hline 2 & Adicionar mais categorias (cidades, objetos, substantivos coletivos...) & Aprimoramento \\
\hline 3 & Adicionar um som enquanto o Sphero está girando & Aprimoramento \\
\hline \multirow{8}{*}{4} & Incluir algumas dicas para adivinhar a palavra & Nova funcionalidade \\
\hline & Adicionar a possibilidade de digitar a palavra inteira quando já sabe a palavra & Nova funcionalidade \\
\hline & Descontar pontos quando o jogador errar a tentativa & Nova funcionalidade \\
\hline & $\begin{array}{c}\text { Equilibrar mais o jogo oferecendo pontuações diferentes dependendo da } \\
\text { dificuldade da palavra }\end{array}$ & Nova funcionalidade \\
\hline & Exibir por mais tempo a palavra antes de exibir a roleta & Aprimoramento \\
\hline & Adicionar um som quando a palavra é descoberta & Aprimoramento \\
\hline & Inserir a tradicional figura da forca & Nova funcionalidade \\
\hline & Colocar um som para quando acertar ou errar uma letra & Aprimoramento \\
\hline \multirow{2}{*}{5} & As letras deveriam ser coloridas & Aprimoramento \\
\hline & Listar as letras que corretas & Aprimoramento \\
\hline \multirow{4}{*}{6} & Adicionar um som para erro & Aprimoramento \\
\hline & Listar as letras que estão erradas & Aprimoramento \\
\hline & Aparecimento gradual dos membros do corpo na forca & Nova funcionalidade \\
\hline & Colocaria um ícone para indicar que houve um erro & Aprimoramento \\
\hline \multirow{3}{*}{7} & Adicionar som nos erros & Aprimoramento \\
\hline & Aparecer de forma gradual os membros do corpo na forca quando houver erros & Nova funcionalidade \\
\hline & Colocar som nos acertos e erros & Aprimoramento \\
\hline \multirow{5}{*}{8} & Utilizar operações matemáticas diferentes (somas, multiplicações, potências...) & Nova funcionalidade \\
\hline & $\begin{array}{l}\text { Deixar mais claro que a pontuação tem relação com a soma das operações } \\
\text { anteriores }\end{array}$ & Aprimoramento \\
\hline & Adicionar som e/ou luzes & Aprimoramento \\
\hline & Adicionar frases de estímulo do tipo “Parabéns, você conseguiu!” & Aprimoramento \\
\hline & $\begin{array}{l}\text { Transformar a pontuação em itens que podem ser usados nas fases seguintes } \\
\text { (para desbloquear dicas, regirar a roleta...) }\end{array}$ & Nova funcionalidade \\
\hline
\end{tabular}

\subsection{Da Autoavaliação de Emoções}

A seguir, analisamos a resposta afetiva dos participantes, professoras e crianças, em relação ao sistema desenvolvido.

O primeiro item analisado foi a Satisfação. É possível observar na Figura 10 à esquerda que as professoras tiveram uma resposta positiva (a moda nessa amostra foi 9) para esse aspecto. Elas relataram que girar o Sphero era uma atividade divertida. Uma professora citou que o sistema tinha "aplicabilidade pedagógica”, enquanto outra mencionou: “Está bem de acordo com a faixa etária trabalhada”. Entre as crianças (Figura 10 à direita), observou-se que 100\% dos participantes ficaram totalmente satisfeitos com o sistema. Além disso, pudemos perceber que os participantes estavam torcendo para os demais colegas enquanto eles giravam o Sphero, para tentar uma pontuação maior. Quando perguntados sobre o que mais tinham gostado no jogo, uma das crianças respondeu: “dos desafios”.

No aspecto Motivação, pudemos perceber que professoras se sentiram menos motivadas que as crianças. Dentre o grupo de professoras, para esse aspecto, 5 professoras tiveram uma resposta positiva (variando entre 7 e 9), 3 apresentaram uma resposta neutra (variando entre 4 e 6) e apenas uma apresentou uma resposta afetiva negativa (variando entre 1 e 3). Uma das professoras relatou que a atividade se torna desmotivadora quando o participante descobre a palavra, mas tem que continuar girando a roleta para terminar de preencher a palavra. Outra professora relatou que a pontuação final, funcionalidade sugerida por elas próprias na primeira Oficina, também poderia ser desmotivadora: "Acredito que quando estamos brincando, não precisamos nos preocupar com notas, pontos ou julgamentos externos, somente brincar”; o que 
parecia a elas uma boa ideia durante design, não se mostrou mais uma boa solução no momento da avaliação durante uso.
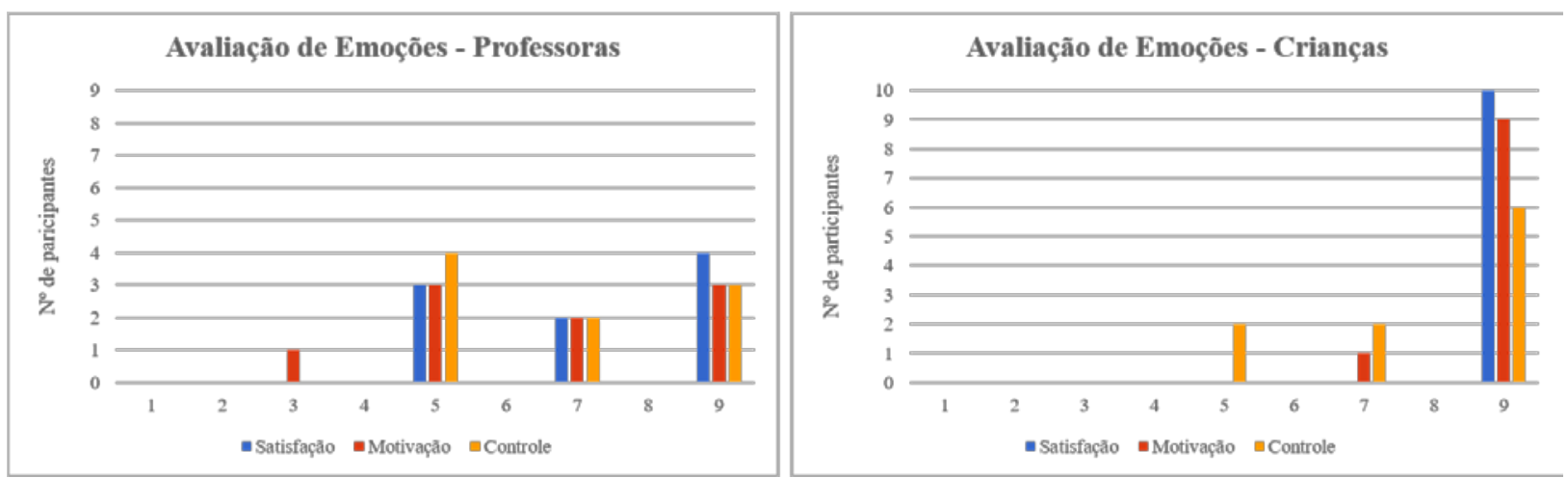

Figura 10: À esquerda, resultado da autoavaliação das professoras; à direita, a autoavaliação das crianças. Fonte: dos autores.

Para as crianças, nove dos dez participantes se sentiram completamente motivados durante o uso do sistema. No início da Oficina, quando as crianças descobriram que eles iam utilizar um jogo com o Sphero, houve gritos de empolgação e enquanto o pesquisador mostrava um exemplo de como usar o sistema, elas davam as respostas em uníssono. O uso de um dispositivo novo pode ter contribuído para os resultados obtidos. Entretanto, foi possível observar que quando as crianças não conseguiam acertar as letras de uma palavra, elas aparentavam ficar chateadas. Isso sugere que a funcionalidade de dicas proposta pelas professoras na avaliação das telas pode melhorar essa situação. Algumas crianças relataram que as contas de multiplicação eram muito simples, enquanto outras relataram que as contas eram difíceis, o que pode indicar que outras expressões matemáticas e valores devem ser utilizados para a pontuação, de modo a tornar a fase da pontuação mais desafiadora conforme o conhecimento da criança que está jogando. Na Oficina, as crianças superaram as dificuldades de descobrir letras que se encaixavam nas palavras e com as contas de multiplicação, colaborando entre si: alunos mais velhos ajudaram os mais novos.

Por fim, em relação ao aspecto Controle, pudemos notar que a maior parte das crianças considerou o sistema de fácil manipulação, enquanto que uma parcela menor de professoras teve essa opinião. Observamos que, entre o grupo das professoras, algumas tentavam manipular a roleta de pontos por meio da representação digital no smartphone ao invés de utilizar o Sphero, que estava ao lado do smartphone. Apesar de as próprias professoras terem proposto o uso do Sphero como roleta, elas ficavam confusas em relação a alternância entre os dispositivos. Esse comportamento, apesar de não ter sido observado no grupo de crianças, sugere que a representação digital deve ser revisitada, para que o desenho lembre o usuário que o outro dispositivo deve ser utilizado. Já no grupo de crianças, observamos que algumas tentavam dar leves toques no Sphero durante o seu movimento de rotação, para fazer com que ele parasse de rodar mais rapidamente ou para tentar ajustar em qual pontuação o dispositivo ia parar.

\subsection{Do Uso e Outras Observações}

Para coletar alguns dados adicionais de interação, foi implantado um sistema de logs, que indicava o início e fim da jogada, o início e fim de cada etapa (adivinhação e multiplicação) e a pontuação final do jogador. Para cada rodada na fase de adivinhação, foram salvos os dados sobre a pontuação para aquela rodada, obtida depois de girar o Sphero, a letra que o jogador tentou acertar e quantas vezes a letra aparecia na palavra a ser descoberta. Para a etapa da multiplicação, foram salvos os dados da letra, do resultado da multiplicação esperado e o digitado pelo jogador toda vez que o usuário clicava no botão para conferir os valores. 
Com esses dados, foi possível obter algumas informações, como o tempo usado pelos jogadores em cada fase, bem como saber quantas tentativas os jogadores tiveram que realizar na fase de adivinhação e multiplicação para finalizar a sua jogada.

Na Oficina com o grupo de professoras, cada um dos participantes levou em média 04:12 minutos para completar a atividade inteira, sendo que o participante mais rápido levou aproximadamente 2 minutos, enquanto que o mais lento levou por volta de 7 minutos. A fase de adivinhação tomou a maior parte da jogada, sendo que os jogadores gastaram em média 3 minutos nessa etapa. A etapa da multiplicação levou em média 1,2 minutos para ser concluída.

Já na Oficina realizada com o grupo de alunos, cada um dos participantes levou em média 04:18 minutos para completar a atividade inteira, sendo que o participante mais rápido e o mais lento levaram respectivamente aproximadamente 2 e 7 minutos. Com resultados bastante semelhantes aos das professoras, a fase de adivinhação tomou o maior tempo da jogada.

Com resultados semelhantes entre professoras e alunos, foram necessárias, em média, 8 tentativas (sendo 5 corretas e 3 erradas) para descobrir as palavras nas jogadas.

Notou-se também que em nenhum dos dois grupos houve erros na fase de multiplicação. Entretanto, quando a palavra continha muitas letras diferentes, algumas das multiplicações ficavam "escondidas", havendo a necessidade de rolar a tela do smartphone para terminar de preencher as multiplicações. Nessas situações, observamos que os participantes só resolviam as contas visíveis na Tela 7, e não tentavam rolar a tela para terminar de resolver as outras contas. Isso indica que melhorias nessa tela devem ser feitas para facilitar a visibilidade ao usuário.

Além disso, os usuários também tinham dificuldade em entender como deveria ser o preenchimento com o resultado da multiplicação: para cada uma das contas de multiplicação, era necessário que o usuário tocasse na linha em branco que aparece na frente de cada uma das contas para que ele pudesse digitar o resultado. Esse comportamento sugere que as instruções exibidas para a fase de multiplicação poderiam ser melhoradas (Tela 7), e que o design da tela poderia ser melhorado para a ação ficar mais transparente para o usuário.

\subsection{Discussão}

Na Oficina 1, em que houve atividades de ideação do sistema, a principal dificuldade sentida pelas professoras foi a "materialização" de uma ideia nova. Apesar de as técnicas de brainstorm e braindraw terem uma base em comum para processos de ideação, que consiste em imaginar soluções e criar representações, em geral em papel e com canetas, as queixas maiores foram relacionadas à técnica de braindraw. Uma possível explicação para esse comportamento é que gerar ideias para o uso do Sphero em aplicativos de contexto educacional esteja mais próximo da criação de planos de aula ou de propostas pedagógicas, atividades comuns realizadas por professoras em seu dia a dia. Entretanto, propor telas de design de um aplicativo para smartphone, para algumas professoras pode parecer inatingível. Esse desconforto gerado no primeiro contato com as técnicas de DP poderia ser diminuído, ou até mesmo evitado, com o envolvimento de times multidisciplinares na atividade de braindraw, com a participação de designers, desenvolvedores, especialistas em IHC e outras partes interessadas nas atividades de DP.

Na Oficina 2, na qual o protótipo do Gira Letra foi utilizado e avaliado pelas professoras, observamos que elas estavam interessadas em saber se o protótipo que elas tinham ajudado a construir seria bem aceito pelo público final, já que uma das primeiras perguntas feitas foi "Você já fez [a atividade] com as crianças? Depois você me conta se deu certo!”. Elas ficaram empolgadas em utilizar o sistema e reconheceram, no protótipo utilizado, elementos que elas haviam proposto na Oficina 1, como por exemplo, a associação entre a pontuação produzida pelo giro do Sphero e a escolha da letra que é feita logo em seguida. Observamos a necessidade de 
mais iterações no ciclo de design para a construção de um produto ainda melhor: na segunda Oficina as professoras encontraram oportunidades para aprimoramentos e propostas de novas funcionalidades que elas não tinham observado na primeira. É o caso da funcionalidade para preencher a palavra inteira sem a necessidade de girar a roleta por tentativa de letra, para evitar casos em que já se saiba a palavra inteira.

Observamos que, mesmo sendo inicialmente planejado para ser um jogo individual, habilidades de colaboração e socialização entre as crianças (Figura 11 à esquerda) foram promovidas com o uso do sistema, já que as crianças se organizavam para ajudar os que ainda tinham dificuldades com as contas de multiplicação, ou quando não conseguiam concluir uma palavra depois de várias tentativas. Por meio dos resultados do SAM, pudemos observar que o sistema Gira Letra produziu uma resposta afetiva positiva nas crianças, e foi possível observar sinais de divertimento. As crianças também não apresentaram dificuldades para controlar o sistema, e inclusive não tiveram problemas em diferenciar a versão da roleta virtual da sua versão tangível com o uso do Sphero.

Apesar de existir uma grande preocupação por parte das professoras para suavizar a pontuação que a criança adquire no final de uma adivinhação, esse não pareceu ser um problema para as crianças, que gostaram de anotar seus pontos na lousa (Figura 11 à direita) e estavam torcendo para que os colegas conseguissem uma pontuação mais alta, e fizeram questão de eles mesmos fazerem a soma final. Isso sugere que tornar as crianças parte do time de desenvolvimento do produto, para a participar das sessões de design do aplicativo, poderá trazer novos aspectos ao design da solução.
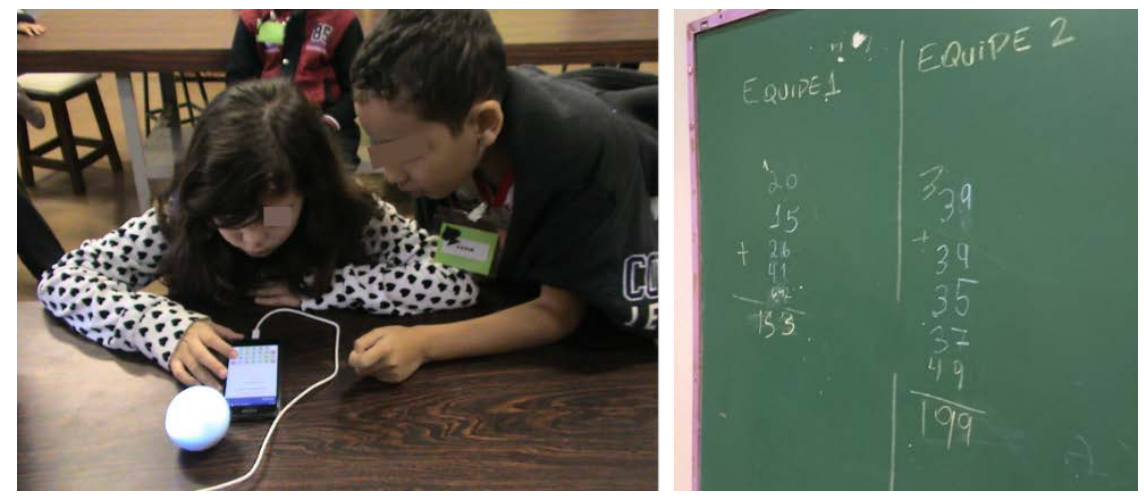

Figura 11: À esquerda, membros da equipe se ajudando; à direita, pontuação gerenciada pelas próprias crianças. Fonte: dos autores.

Com resultados numéricos semelhantes, crianças e professoras levaram em média o mesmo tempo para concluir as atividades e utilizaram em média o mesmo número de tentativas para adivinhar as palavras. Esse resultado pode indicar que as crianças não encontraram barreiras cognitivas ou de outra natureza durante o uso do sistema.

Apesar dos resultados numéricos muito semelhantes no que se refere ao tempo e performance para concluir as atividades no uso do sistema, observamos que as respostas afetivas entre adultos e crianças são muito diferentes. Uma hipótese que explicaria esse comportamento é o fato de o grupo de adultos assumirem o papel de 'professoras' na Oficina 1, propondo objetivos educacionais e um método de avaliação/pontuação conservadores, e na Oficina 2 assumirem o papel da criança que vai jogar e aprender usando o sistema. Um exemplo que ajuda a ilustrar essa hipótese é uma das funcionalidades sugeridas pelas professoras na Oficina 2, que visa facilitar o preenchimento da palavra inteira sem a necessidade de girar a roleta para cada tentativa de letra. Apesar de ter sido sugerida pelas próprias professoras, a fase de multiplicação poderia ficar comprometida com essa nova abordagem (diminuindo a quantidade de contas matemáticas feitas), 
de modo a prejudicar um dos objetivos pedagógicos propostos na Oficina 1. E, apesar de as professoras julgarem essa solução utilizada no protótipo como “desmotivadora”, as crianças não mostraram sinais de se sentirem desmotivadas em terem que girar o Sphero mesmo após julgarem já terem adivinhado a palavra: a cada giro do Sphero eles torciam para um valor alto na roleta, e a cada letra correta que confirmava as suas suspeitas que a palavra era a correta, as crianças vibravam ainda mais.

Mesmo com os bons resultados obtidos na primeira iteração do processo conduzido neste trabalho, observa-se que o envolvimento das crianças pode, ainda, ser estendido a outras etapas do processo de design, ampliando o seu potencial de influência no produto final. Por exemplo, poderíamos explorar a avaliação da satisfação com cada uma das telas pelas crianças, investigando suas contribuições. Como as crianças têm menor capacidade de comunicar pensamentos abstratos, possuem limitações cognitivas e se expressam em ações mais do que em palavras (Druin, 2002), ressaltamos que o envolvimento delas também traz mais desafios para o processo. A avaliação das telas também poderia ser realizada por especialistas em IHC, que poderiam utilizar heurísticas de usabilidade na avaliação, trazendo novos aspectos a serem considerados. Além disso, como este trabalho focou no envolvimento ativo de professores na criação de sistemas que utilizam o Sphero como interface tangível, é possível, ainda, conduzir outros trabalhos para avaliar se os objetivos pedagógicos almejados pelas professoras no momento em que elas propuseram o Gira Letra foram atingidos ou transformados durante o uso do sistema.

\section{Conclusão}

Num momento em que o desenvolvimento de tecnologias digitais se espalha para o cotidiano das pessoas cada vez mais, nos perguntamos se os professores deveriam continuar como consumidores passivos da tecnologia que designers apresentam a eles, ou se, ao contrário, poderiam ser ativos no processo de criação dessa tecnologia. Buscando respostas a essa indagação, neste trabalho exploramos o uso de algumas técnicas do Design Participativo no processo de design e desenvolvimento de um aplicativo educacional para o contexto do público infantil, que utilizasse o Sphero como uma interface tangível. O trabalho resultou no sistema Gira Letra, composto de um aplicativo para Android que utiliza o Sphero como representação física de uma roleta de pontos virtual, ainda em sua primeira versão; o sistema foi resultado das práticas participativas das professoras como autoras e teve dois objetivos educacionais intencionados por elas: aumentar o vocabulário e trabalhar concomitantemente soluções de expressões matemáticas.

Em síntese, o processo utilizado nesse trabalho investigou e promoveu a participação ativa de professores na elaboração de sistemas tecnológicos voltados ao contexto educacional. Os resultados foram positivos e, ainda, sugerem que o processo poderia ser facilitado com o envolvimento de outros perfis de profissionais nas Oficinas de design. Os resultados também sugerem, para investigação futura, que o produto resultante poderia se beneficiar da participação direta das crianças, em outras etapas do processo, como parceiros de design, embora acrescentando novos desafios.

\section{Agradecimentos}

Agradecemos a todos os alunos, professores e funcionários do PRODECAD (Programa de Desenvolvimento da Criança e do Adolescente), ao Grupo Gestor de Benefícios Sociais da Unicamp (GGBS), aos pesquisadores do grupo de pesquisa Interação Humano-Artefato Digital 
(InterHAD) e ao Instituto de Computação da Unicamp. Apoiaram o trabalho: CNPq (\#306272/2017-2) e FAPESP (\#2015/16528-0).

\section{Referências}

Arantes, F. L., Amiel, T., Miranda, L. C., Martins, M. C. e Baranauskas, M. C. C. (2012). Laptops Educacionais em Escolas Públicas: Primeiros Resultados de uma Abordagem Socio-Técnica. In Revista Brasileira de Informática na Educação, Vol 20, N 2, 31-43. [GS Search]

Baranauskas, M. C. C. e Carbajal, M. L. (2017). The Social Nature of Programming: Children and Fluency. In: Kurosu M. (eds) Human-Computer Interaction. Interaction Contexts. HCI 2017. Lecture Notes in Computer Science, vol 10272. Springer, Cham. doi: 10.1007/978-3319-58077-7_23. [GS Search]

Baranauskas, M. C. C. e Posada, J. E. G. (2017). Tangible and Shared Storytelling: Searching for the Social Dimension of Constructionism. In Proceedings of the 2017 Conference on Interaction Design and Children (IDC '17). ACM, New York, NY, USA, 193-203. doi: 10.1145/3078072.3079743. [GS Search]

Bradley, M. M. e Lang, P. J. (1994). Measuring emotion: the self-assessment manikin and the semantic differential. In Journal of behavior therapy and experimental psychiatry, 25 (1), 4959. doi: 10.1016/0005-7916(94)90063-9. [GS Search]

Braz, L. M., Ramos, E. S., Bonedetti, M. L. P. e Hornung, H. H. (2016). Design de tecnologia e educação inclusiva: explorando o espaço do problema. In Anais do Simpósio Brasileiro de Informática na Educação, volume 27, page 757-766. doi: 10.5753/cbie.sbie.2016.757. [GS Search]

Druin, A. (1999). Cooperative inquiry: developing new technologies for children with children. In Proceedings of the SIGCHI conference on Human Factors in Computing Systems (CHI '99). ACM, New York, NY, USA, 592-599. doi: 10.1145/302979.303166. [GS Search]

Druin, A. (2002). The role of children in the design of new technology. In Behaviour and Information Technology, 21 (1), 1-25. doi: 10.1080/01449290110108659. [GS Search]

Hourcade, J. P. (2015). Child-Computer Interaction. CreateSpace Independent Publishing Platform, San Bernardino, CA. [GS Search]

Ishii, H. e Ullmer, B. (1997). Tangible bits: towards seamless interfaces between people, bits and atoms. In Proceedings of the ACM SIGCHI Conference on Human factors in computing systems (CHI \&\#39;97). ACM, New York, NY, USA, 234-241. doi: 10.1145/258549.258715. [GS Search]

Ishii, H. (2008). Tangible bits: beyond pixels. In Proceedings of the 2nd international conference on Tangible and Embedded Interaction (TEI '08). ACM, New York, NY, USA, XV-xxv. doi: 10.1145/1347390.1347392. [GS Search]

Matsunaga, R. M., Borges, M. A. F. e Moraes, R. L. O. (2015). Desenvolvimento de um jogo educativo para crianças com hemofilia. In Revista Brasileira de Informática na Educação, Vol 23, N 2, 59-69. doi: 10.5753/RBIE.2015.23.02.60. [GS Search]

Muller, M. J., Haslwanter, J. H. e Dayton, T. (1997). Participatory Practices in the Software Lifecycle. In Handbook of Human-Computer Interaction, M.G.Helander, T.K.Landauer, P.V.Prabhu (eds.). Elsevier Science, pp. 255-297. doi: 10.1016/B978-044481862-1.50077-7. [GS Search] 
Pantoja, L. S., Hourcade, J. P., Diederich, K., Crawford, L. e Utter, V. (2017). Developing StoryCarnival: exploring computer-mediated activities for 3 to 4 year-old children. In Proceedings of the 16th Brazilian symposium on human factors in computing systems (IHC'17). doi: 10.1145/3160504.3160570. [GS Search]

Posada, J. E. G., Hayashi, E. e Baranauskas, M. C. C. (2014). On Feelings of Comfort, Motivation and Joy that GUI and TUI Evoke. In Design, User Experience, and Usability. User Experience Design Practice: 273-284. Springer International Publishing. doi: $\underline{10.1007 / 978-3-319-07638-}$ 6_27. [GS Search]

Read, J. C. e Bekker, M. M. (2011). The nature of child computer interaction. In Proceedings of the 25th BCS Conference on Human-Computer Interaction (BCS-HCI '11). British Computer Society, Swinton, UK, UK, 163-170. [GS Search]

Russell, J. A. e Mehrabian, A. (1977). Evidence for a three-factor theory of emotions. In Journal of research in Personality, 11(3), 273-294. doi: 10.1016/0092-6566(77)90037-X. [GS Search]

Sánchez, I., Cortés, M., Riekki, J. e Oja. M. (2011). NFC-based interactive learning environments for children. In Proceedings of the 10th International Conference on Interaction Design and Children (IDC '11). ACM, New York, NY, USA, 205-208. doi: 10.1145/1999030.1999062. [GS Search]

Shaer, O. e Hornecker, E. (2010). Tangible User Interfaces: past, present, and future directions. Foundations and Trends in Human-Computer Interaction, vol. 3, no. 12, 1-137. doi: 10.1561/1100000026. [GS Search]

Soleimani, A., Green, K. E., Herro, D. e Walker, I. D. (2016). A Tangible, Story-Construction Process Employing Spatial, Computational-Thinking. In Proceedings of the The 15th International Conference on Interaction Design and Children (IDC '16). ACM, New York, NY, USA, 157-166. doi: 10.1145/2930674.2930703. [GS Search]

Sylla, C., Branco, P., Coutinho, C. e Coquet, E. (2012). TUIs vs. GUIs: comparing the learning potential with preschoolers. Personal and Ubiquitous Computing, Springer, Vol 16, No. 4, 421-432. doi: 10.1007/s00779-011-0407-z. [GS Search]

Zuckerman, O., Arida, S. e Resnick, M. (2005). Extending tangible interfaces for education: digital montessori-inspired manipulatives. In Proceedings of the SIGCHI Conference on Human Factors in Computing Systems (CHI '05). ACM, New York, NY, USA, 859-868. DOI: 10.1145/1054972.1055093. [GS Search] 